\title{
Pengembangan Pariwisata Kampung Fashion Etnik DI SUKOHARJO
}

\author{
AQILATUL MUYASSAROH ${ }^{1}$ \\ PROGRAM STUDI ARSITEKTUR \\ FAKULTAS TEKNIK \\ UNIVERSITAS SEBELAS MARET, SURAKARTA \\ email: aqilamuyassarohsudiro@gmail.com \\ OFITA PURWANI ${ }^{2}$ \\ PROGRAM STUDI ARSITEKTUR \\ FAKULTAS TEKNIK \\ PUSAT INFORMASI DAN PEMBANGUNAN WILAYAH (PIPW), LPPM \\ UNIVERSITAS SEBELAS MARET, SURAKARTA \\ AGUNG KUMORO WAHYU $W^{3}$ \\ PROGRAM STUDI ARSITEKTUR \\ FAKULTAS TEKNIK \\ PUSAT INFORMASI DAN PEMBANGUNAN WILAYAH (PIPW), LPPM \\ UNIVERSITAS SEbELAS MARET, SURAKaRTa
}

\begin{abstract}
Traditional industries can be utilized for cultural and economic preservation. One of them is ethnic fashion which is currently in favor of the fashion designers in Indonesia. Sukoharjo regency is one of the areas in Central Java that has the potential of ethnic fashion which can be the number of craftsmen as well as the number of fabric motifs. This ethnic fashion village aims to accommodate ethnic fashion craftsmen in Sukoharjo in order to further develop the tourist industry. In the other hand, architecture is a knowledge that can make the tourism happen. The way is collaborate the component that must have by tourism destination with aspect of architecture like structure, room division, utility, and many more.
\end{abstract}

Keywords: ethnic fashion, Sukoharjo, tourism, village

\section{PENDAHULUAN}

Pemerintah RI merencanakan Indonesia sebagai 'Kiblat fashion muslim dunia 2020' terkait dengan berkembangnya desainer fashion muslim di Indonesia dan penggunaannya sejak tahun 2010. Pesatnya perkembangan fashion muslim hingga ke luar negeri ini dimanfaatkan para desainer untuk mempromosikan kain etnik nusantara sebagai bahan utama rancangan mereka agar lebih dikenal luas. Apabila rencana ini terwujud, maka akan memberikan dampak positif bagi daerah dengan potensi fashion etnik, salah satunya Kabupaten Sukoharjo.
Berdasarkan data yang dihimpun dari berbagai sumber seperti mediaindonesia.com dan solopos.com didapatkan jumlah para pengrajin kain tradisional antara lain batik terdapat 61 menengah ke atas dan 107 pengrajin kecil, Tenun 294, jumputan di Desa Wirun dan Cemani, serta Lurik tersentralisasi di tiga desa.

Kesempatan berkiprah di dunia fashion etnik yang tidak hanya batik, tetapi juga ada tenun lurik dan jumputan, dibutuhkan wadah yang tersentralisasi untuk memperkenalkan fashion etnik 
Sukoharjo dan pengrajinnya sehingga tidak perlu menyambangi tempat produksi masing-masing yang menyebar dan belum tentu mudah ditemukan.

Dikutip dari m.solopos.net pada tanggal 4 Desember 2015 Menteri Koordinator Bidang Pembangunan Manusia dan Kebudayaan, Puan Maharani melakukan kunjungan kerja ke Sukoharjo sekaligus mencanangkan program "Gema Berbudaya" atau Gerakan Masyarakat Usaha Berbasis Budaya. Program tersebut bertujuan mengembangkan sektor industri dan usaha kecil menengah di Sukoharjo.

Keberadaan wisatawan, mulai membayar parkir kendaraan, makan di warung atau kedai, serta berbelanja oleh-oleh dapat membuka peluang untuk warga sekitar memperoleh pendapatan dengan resiko rendah.

Merujuk pada aspek pengembangan obyek wisata yang digagas pemerintah di atas, terutama pada poin kedua tentang pengembangan obyek wisata, maka sesuai dengan aspek komponen wisata yang harus dipenuhi yakni penawaran yang meliputi : (1) Atraksi, (2) Infrastruktur, (3) Akomodasi, (4) Fasilitas, dan (5) Transportasi serta permintaan dari pengunjung wisata dan masyarakat setempat [Yoeti, 1983; Pendit, 1986].

Program pemerintah yang memasarkan industri secara pariwisata tersebut mendorong industri fashion etnik ini menjadi lebih potensial, karena pariwisata adalah salah satu industri yang meningkatkan pertumbuhan ekonomi secara cepat dalam hal kesempatan kerja, pendapatan, taraf hidup dan dalam mengaktifkan produksi lainnya. Oleh karena itu pariwisata disebut dapat merangkul semua potensi menjadi dapat dikonsumsi lebih luas seperti sektor industri kerajinan, cinderamata, kuliner, penginapan dan transportasi [Wahab, 1975].
Pengguna atau user di dalam kampung fashion etnik terkelompokkan ke dalam jenis penyedia dan penikmat berbagai atraksi, pengrajin yang selalu menghasilkan karya, keterbatasan daya tampung, dan tidak menentunya jumlah wisatawan setiap harinya. Pengguna dari sisi konsumen, yakni wisatawan dan dari sisi penyedia layanan atau fashion etnik adalah staf pengelola kampung fashion etnik dan pengrajin.

Diharapkan fasilitas ini dapat mempromosikan potensi Kabupaten Sukoharjo dalam hal fashion etnik. Juga mampu menampung harapan para wisatawan dan pengguna atau pengrajin fashion etnik dalam mewadahi aktivitas pemasaran, danatraksi untuk wisatawan seperti melihat langsung proses produksi, mencoba melakukan proses produksi, dan melihat pertunjukkan peragaan busana secara langsung, sehingga dapat meningkatkan pendapatan daerah serta menyejahterakan pengrajin agar terus berkiprah.

Lokasinya berada di Kabupaten Sukoharjo serta mengangkat industri fashion etnik, maka perancangannya perlu menyesuaikan bangunan sekitar yang merupakan pemukiman penduduk. Hal ini diperlukan untuk memenuhi ekspektasi pengunjung tentang lokasi fashion etnik Sukoharjo yang sebenarnya serta nyaman bagi masing-masing pengrajin atau pedagang yang berasal dari lingkungan yang sama atau setipe.

Bentuk kampung digunakan karena menyesuaikan realita yang ada pada para pengrajin sehingga mereka tetap berkegiatan secara alami seperti kebiasaan aslinya. Hal ini sesuai dengan pendapat bahwa wisatawan termotivasi untuk menempuh perjalanan hingga ke luar negeri tidak hanya untuk melihat kehidupan sehari-hari orang-orang di tempat lain. Mereka membuktikan keaslian dan kebenaran waktu dan 
tempat yang jauh dari tempat mereka sendiri [Urry, 2002].

Bentuk kampung fashion etnik memang sudah banyak dikembangkan di daerah penghasil batik lainnya seperti di Solo ada Kampung Batik Laweyan dan Kauman, di Cirebon ada Kampung Batik Trusmi, di Pekalongan ada Kampung Batik Pesindon, di Jogjakarta ada Kampung Batik Giriloyo. Meskipun sudah dinamakan sebagai kampung fashion etnik fashion etnik, bukannya kampung batik akan menimbulkan persepsi bahwa ini adalah tiruan dari kampung-kampung tersebut. Maka dari itu, wisatawan perlu diberi keaslian dari brand kampung fashion etnik fashion etnik ini yang sebenarnya dan perbedaannya dengan kampung-kampung tersebut.

Keaslian ini membutuhkan teori yang dibahas oleh Nezar Al-Sayyad [2001] dalam bukunya Consuming Tradition, Manufacturing Heritage yang membahas memproduksi warisan untuk tujuan pariwisata.

Dari pemaparan tersebut dapat disimpulkan bahwa permasalahan desain yang harus diselesaikan dalam riset ini di antaranya : (A) komponen wisata; (B) pengguna (user); (C) penentuan lokasi tapak; (D) keaslian kampung fashion etnik.

\section{METODE PERANCANGAN}

Langkah pertama dalam riset pengembangan pariwisata ini adalah menganalisis peraturan pemerintah Kabupaten Sukoharjo terkait dengan Program Wisata Makmur dan RTRW peraturan tata guna lahan untuk menentukan lokasi tapak yang sesuai.

Proses selanjutnya yaitu menganalisis komponen wisata yang wajib disediakan saat membuat sebuah pariwisata, diantaranya atraksi, infrastruktur, dan fasilitas yang harus diselesaikan dengan teori arsitektur utamanya untuk mendapatkan pariwisata yang asli, tidak hanya sekadar tiruan produk yang sudah ada.

Langkah terakhir yakni menganalisis elemen-elemen arsitektur yakni ruang terkait dengan pencapaian; aksesibilitas; sirkulasi; daya tampung; dan kesesuaian dengan kegiatan, struktur terkait dengan kekuatan, utilitas terkait dengan kemampuan bangunan untuk melayani dan membuat nyaman penggunanya dalam berkegiatan.

\section{HASIL DAN PEMBAHASAN}

\subsection{Komponen Wisata}

Fungsi proyek tugas akhir ini adalah mendapatkan perencanaan dan perancangan untuk mempromosikan dan memamerkan karya pengrajin fashion etnik Sukoharjo. Di sisi lain, tujuan didirikannya kampung fashion etnik adalah sebuah kawasan wisata belanja, edukasi, dan seluk beluknya tentang fashion etnik di Sukoharjo agar lebih dikenal. Untuk mengarahkan arsitektur dan pariwisata maka harus memenuhi komponen wisata, yakni penawaran yang meliputi : (1) Atraksi, (2) Infrastruktur, (3) Akomodasi, (4) Fasilitas, dan (5) Transportasi serta permintaan dari pengunjung wisata dan masyarakat setempat [Yoeti, 1983].

Komponen wisata kegiatan atau atraksi wisata yang harus dipenuhi tidak terdapat standar untuk menentukan jenis atraksi, untuk itu dilakukan proses penyesuaian dari preseden atraksi wisata diantaranya terdapat atraksi pertunjukkan fashion (fashion show) seperti di Purawisata, melihat proses produksi dan melakukan workshop seperti di Desa wisata Tenganan, berbelanja dengan pemandangan yang indah seperti di Nusa Dua, melihat relief, diorama (miniatur), dan benda-benda bersejarah yang terkait seperti di Monumen Jogja Kembali. 
Aplikasinya dalam kampung fashion etnik adalah sebagai lingkungan baru yang dibina seperti sebuah area pemasaran sekaligus ruang festival karya bagi para pengrajin agar dapat dikenal luas dan lebih berkembang dengan adanya pengaruh kunjungan wisatawan. Regulasinya hanya pada saat jam kerja, dalam artian tidak ada warga yang bermukim, tidak terikat pada normanorma serta tradisi di lingkungan tempatnya berdiri, dan hanya pola tatanannya saja yang menyerupai kampung. Selain itu, dengan format ini fasilitas dan infrastrukturnya menjadi lebih mudah untuk dirawat dan dikembangkan karena hanya bagian dari kampung fashion etnik.

Sosok kampung fashion etnik fashion etnik masih tidak berhenti pada kegiatan wisata berjual-beli, memamerkan proses pengerjaan, melihat proses pengerjaan, dan mencoba langsung proses pengerjaan yang dilakukan pengrajin atau pedagang dengan wisatawan. Melainkan harus ada ruang untuk memperagakan fashion tersebut agar semakin menarik wisatawan. Hal ini sangat perlu karena belum ada tempat khusus untuk peragaan busana dan biasanya dilakukan di mall atau hotel di Sukoharjo.

Ruang peragaan busana ini tidak hanya untuk karya pengrajin atau pedagang yang memiliki 'lapak' di kampung fashion etnik ini, namun juga diperuntukan bagi karya pengrajin di luar kampung fashion etnik termasuk para pelajar di bidang fashion etnik Sukoharjo.

Melengkapi atraksi atau kegiatan wisata yang ditekankan pada program pemerintah yang disebutkan sebelumnya maka diperlukan sesuatu yang bernilai sejarah dalam bentuk museum yang dapat menceritakan bagaimana perjalanan fashion etnik di Sukoharjo secara teatrikal pasif atau patung, fotografi, dan memamerkan peralatan produksi fashion etnik kuno yang tidak dapat dibeli siapapun. Serta untuk menuntaskan rasa ingin memiliki, dibuat dalam bentuk galeri yang berisi stan-stan fashion etnik yang tidak memiliki lapak tetap dan peralatan produksi yang dapat dibeli.

Untuk memenuhi beragam atraksi tersebut maka diperlukan sistem peruangan seperti tabel berikut:

Tabel 2. Sistem Peruangan

\begin{tabular}{|l|l|}
\hline Nama Ruang & Ukuran \\
\hline Retail & 2700 \\
Butik & 1224 \\
\hline Gazebo & 300 \\
Amphi theatre & 120 \\
Taman & 1500 \\
Playground & 150 \\
Sirkulasi & 1242 \\
\hline Food Court & 108 \\
Ruang Makan & 108 \\
Dapur & 60 \\
Booth & 30 \\
\hline Toilet & 400 \\
\hline Ruang & 288 \\
Pameran & 36 \\
Ruang Audio Visual & 36 \\
Gudang & 36 \\
Ruang control panel & 237 \\
Sirkulasi & \\
\hline Ruang catwalk I & 576 \\
Ruang catwalk II & 288 \\
Ruang Ganti & 288 \\
Basecamp & 144 \\
Gudang & 72 \\
Lobi & 144 \\
Ruang Staf Pengelola & 72 \\
Ruang CCTV & 36 \\
Ruang control panel & 36 \\
\hline Ruang pameran & 1200 \\
Ruang CCTV & 36 \\
Ruang audio visual & 36 \\
Lobi & 36 \\
Ruang Staf Pengelola & 144 \\
\hline Ruang Direktur & 36 \\
Ruang Staf & 72 \\
Ruang arsip & 36 \\
Gudang & 36 \\
Lobby & 72 \\
Pantry & \\
\hline
\end{tabular}




\begin{tabular}{|l|l|}
\hline Parkir & 2.755 \\
\hline Masjid & 633 \\
\hline Utilitas & 736 \\
\hline TOTAL (+Sirkulasi) & $\pm 23.988 \mathrm{~m}^{2}$ \\
\hline
\end{tabular}

Sumber : Neufert, 1996; Analisis Penulis, 2017

Aspek infrastruktur yang diperlukan oleh fasilitas wisata harus nyaman dan dapat diakses oleh pengunjung (wisatawan), pengrajin dan pengguna lainnya. Akomodasi yang dimasukkan ke dalam kampung fashion etnik ini dikombinasikan dengan komponen fasilitas yang terdiri atas peruangan untuk menunjang atraksi seperti museum, auditorium, dan amphiteater, dan fasilitas umum seperti parkir, masjid, foodcourt, dan plaza/ruang terbuka. Komponen transportasi yang dimaksud lebih kepada transportasi luar menuju dan dari kampung fashion etnik fashion etnik ini.

\subsection{Pengguna (user)}

Berdasarkan data yang berhasil dikumpulkan Joglosemar, dari Dinas Kebudayaan dan Pariwisata (Disbudpar), Senin (21/3) selama Januari hingga Februari tahun ini tercatat sudah ada sebanyak 617.489 wisatawan (Media and Media 2016). Angka 617.489 wisatawan tersebut adalah untuk waktu selama 60 hari, untuk itu perhitungan sementara setiap harinya rata-rata 10.000 pengunjung. Angka 10.000 wisatawan tersebut jika dialirkan ke kabupatenkabupaten se-eks karesidenan Surakarta maka setiap kabupatennya akan menerima $\pm 1.000 \quad$ wisatawan. Kesimpulannya adalah kampung fashion etnik fashion etnik di Sukoharjo ini harus diproyeksikan dapat menampung 1.000 wisatawan sebagai kuota destinasi wisata Solo Raya. Jumlah 1.000 pengunjung juga harus diimbangi dengan jumlah pengguna lain yakni pengrajin sebagai penyedia fashion etnik beserta atraksinya serta stakeholder yaitu staff yang menjembatani kepentingan wisatawan dan pengrajin.

\subsection{Penentuan Lokasi Tapak}

Site yang dipilih merupakan lahan persawahan seluas $\pm 4 \mathrm{Ha}$ atau 400.000 m2di Jalan Sutawijaya, Desa Pojok, Tawangsari. Site atau tapak ini merupakan satu-satunya kandidat site terpilih karena hanya di tapak inilah yang memenuhi kriteria memiliki potensi fashion etnik terutama batik, tenun, dan lurik karena berada di Tawangsari dengan fungsi tapak sebagai area wisata yang memenuhi luasan minimal setelah ditambah peraturan daerah yang berlaku di dalamnya yakni: GSB $=2 \mathrm{~m}, \mathrm{GSS}=10-$ $15 \mathrm{~m}, \mathrm{KDB}=80 \%, \mathrm{KLB}=3$ lantai.

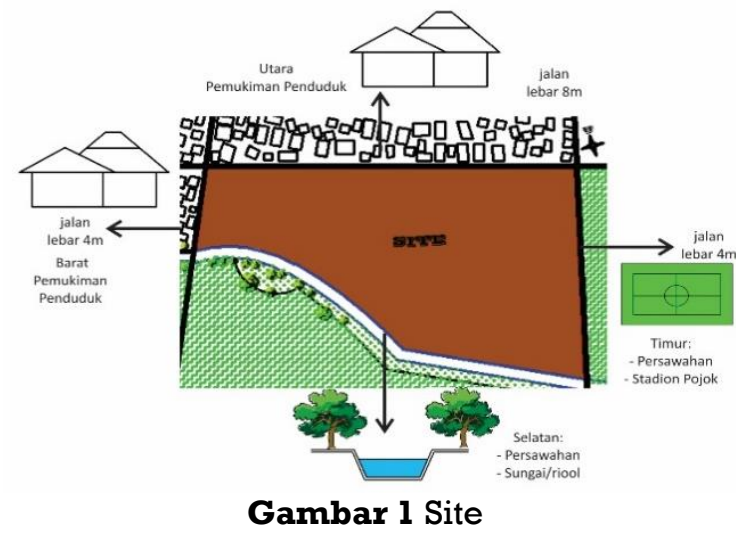

Main Entrance (ME) dan Side Entrance (SE) sebagai pintu masuk menuju site dengan pertimbangan lalu lintas sekitar, servis dan evakuasi, dan kemungkinan pemisahan pencapaian masuk dan keluar agar mempermudah pencapaian wisatawan dan pengguna lain.

Akses pintu masuk sebaiknya dapat dicapai dari segala arah untuk memudahkan akses pengunjung, Pintu masuk bagi pengunjung sebaiknya diletakkan di tempat yang mudah terlihat, dapat ditemui dengan mudah dan sebaiknya didekatkan dengan area lobby.

Pintu masuk bagi karyawan dan staff sebaiknya terpisah dengan pintu masuk pengunjung. Jika perlu digabungkan dengan jalur masuk penerimaan dan pengiriman barang-barang, dengan tangga tersendiri ke ruang penyimpanan atau ganti pakaian, dimana luas ruang 
yang dibutuhkan dihitung 0,4-0,5 m2/orang.

Sirkulasi zona komersial atau belanja memusatkan perhatian pada lantai. Elemen depan fasad menjadi kontak awal, gang beratap dinilai penting bagi wisatawan untuk menghindari cuaca panas sekaligus menyambungkan antar retail yang beragam. 3 divisi horizontal toko yaitu kios, etalase, dan promosi.

Butik dan retail pada kampung fashion etnik ini menggunakan aturan klasik yang dicirikan dengan jendela yan kecil namun cukup untuk display, pintu masuk didekorasi, lantai berbeda dengan jalan, diatas jendela ada tanda pemilik sebagai identitas regional.

Area parkir terletak di sekeliling bangunan dan terintegrasi antara parkir wisatawan dengan parkir pengguna lain seperti pengrajin, pedagang, kru, staf, dan stakeholder untuk memudahkan pengawasan dan pengaturan tata parkir. Drop off untuk pengunjung atau wisatawan di main entrance (pintu masuk utama), sebelum memasuki lapangan parkir baik untuk kendaraan pribadi maupun bus wisata. Kegiatan drop off (bongkar muat) untuk barang-barang staf dan pedagang atau pengrajin dapat dilakukan di SE yang tersedia troli atau gerobak dorong untuk memudahkan pembawaan ke dalam kawasan.

Parkir yang menghadap ke bibir sungai memiliki jarak 5m dengan pembatas dinding parapet (pelindung) setinggi 1,5m agar view-nya dapat dinikmati dari dalam kawasan.

\subsection{Keaslian Kampung Fashion Etnik}

Wisatawan mengharapkan keaslian etnik untuk kepuasan dan pengrajin harus dapat meyakinkan bahwa hanya inilah tempat mendapatkan keaslian tersebut.
Pertunjukkan lain yang diinginkan wisatawan berupa tata pemilihan dan penggunaan bahan yang asli tradisional, tata cara pembuatan, beserta peralatan kunonya seperti pada saat dulu fashion etnik pertama kali diciptakan.

Arsitektur Jawa, kolonial, kontemporer merupakan gaya arsitektur yang telah tumbuh berkembang di Kabupaten Sukoharjo berdasarkan fenomena yang ada di lapangan. Ketiga gaya tersebut telah menyuarakan tampilan perkampungan yang heterogen di lingkungan pengrajin fashion etnik di Sukoharjo karena sama-sama masih bertahan sebagai bentuk bangunan.

Bentuk bangunan yang diharapkan memiliki gaya etnik yang mencerminkan keaslian kampung untuk wisata fashion etnik. Fashion etnik di Sukoharjo tidak memiliki sebuah kampung yang merepresentasikan etnik itu sendiri. Untuk itu, pada analisis bentuk bangunan untuk dapat mencerminkan kampung fashion etnik Sukoharjo dengan memanfaatkan 3 (tiga) komponen yakni:

a. Arsitektur pada bangunan di Sukoharjo.

b. Ornamen motif fashion etnik Sukoharjo.

c. Ekspose bahan material bangunan yang digunakan dan diproduksi di Sukoharjo.

Bentuk bangunan terdiri atas bentuk atraksi belanja, workshop, dan fashion show. Bentuk ruang untuk atraksi belanja dan workshop disatukan dalam sebuah massa karena proses dilakukan oleh pelaku yang sama, yakni pihak pengrajin dan pihak wisatawan. Penyatuan ruang untuk meminimalisasi ruang dan ekspresi bangunan yang terpakai agar lebih optimal, sehingga pengrajin dapat melayani pembelian produk fashion etnik, menghasilkan desain fashion etnik, dan mengajar workshop di satu tempat 
yang sama. Hal ini akan mempermudah pengrajin dalam komunikasi dan pengawasan terhadap area belanja dan workshop.

Butik memiliki bentuk yang lebih besar dan renggang dibanding retail yang cenderung padat dan berhimpitan satu sama lain. Selain itu, untuk memenuhi jumlah retail yang lebih banyak maka bentuk bangunan retail terdiri atas 2-3 lantai sedangkan butik terdiri atas 1-2 lantai saja.

Bentuk kawasan diproses melalui penggabungan arsitektur Jawa, yakni pola tatanan ruang yang meliputi peletakkan komponen pendhopo, pringgitan, dalem ageng, senthong kiwotengen-tengah, dan pawon dengan motif batik tuntum yang merupakan salah satu motif fashion etnik.

Berikut tahapan proses gubahan massa dari perencanaan hinga ke pembagian zona massa (bentuk):

Tabel 3. Tahapan Gubahan Massa

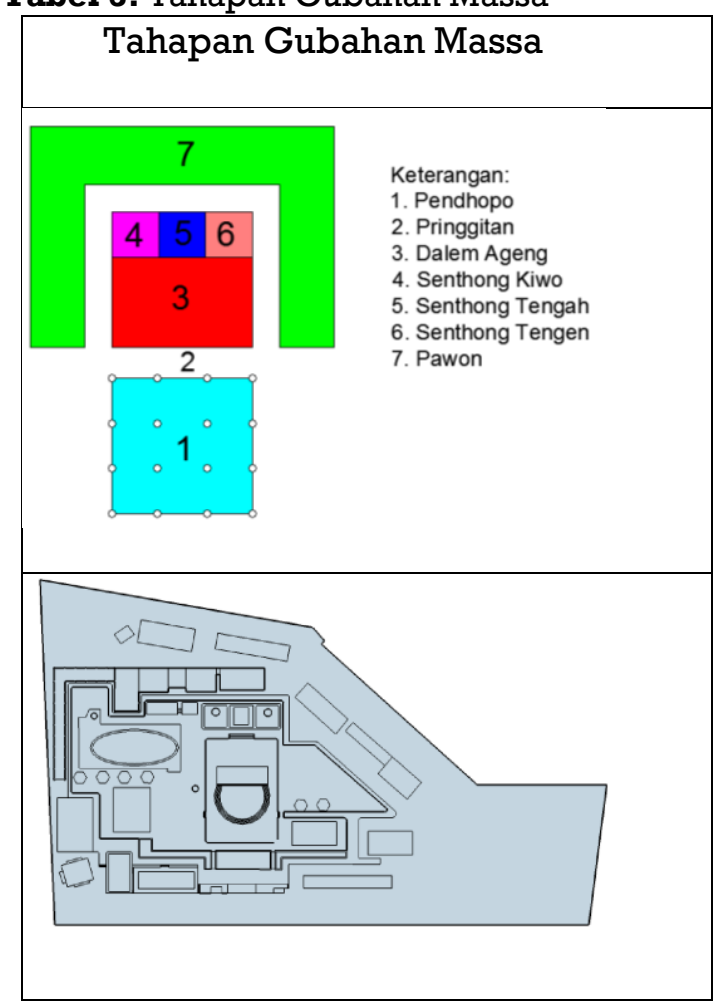

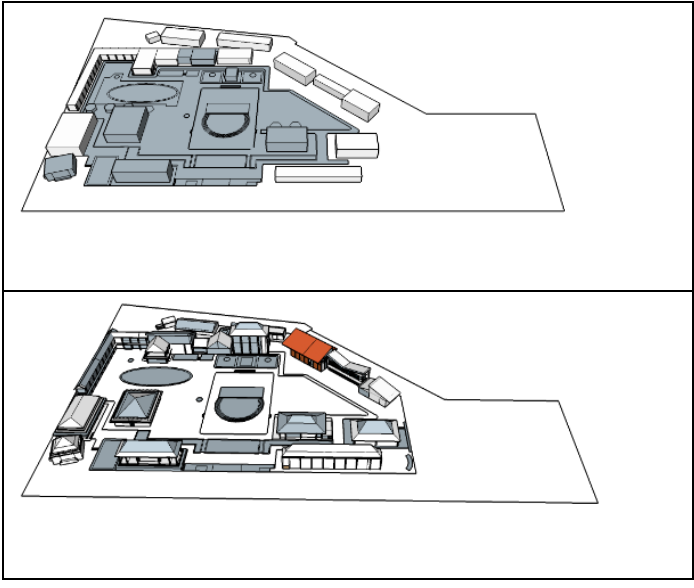

Pola peruangan khas Jawa diaplikasikan ke dalam tatanan massa kawasan. Massa yang digunakan tetap segiempat yang lebih fleksibel dan sederhana. Gubahan massa diidentifikasi dengan perbedaan ketinggian bangunan serta kombinasi atap yang ada di arsitektur kampung Sukoharjo sebagai penanda keaslian.

Tampak diibaratkan sebagai wajah pada bangunan yang diharapkan dapat memancarkan fungsi dan citra estetis yang khas, mengarah pada kejelasan, kewajaran, dan kesinambungan [Soetiadji, 1986].

Sukoharjo merupakan salah satu daerah di Pulau Jawa yang kental dengan budaya Jawa.Terutama di desa-desa seperti Tawangsari yang terlihat dari kerajinan tradisional dan bangunan rumah Jawanya. Hal yang menarik dari kerajinan fashion etnik yang ada di Sukoharjo, daerah Tawangsari khususnya, sebagai lokasi tapak, adalah kekhasan bangunan rumah joglo yang menjadi pabriknya. Masyarakat yang mendirikan pabrikpabrik rumahan fashion etnikini tetap menggunakan rumah tinggalnya yang berupa joglo sebagai tempatnya bekerja.

Sistem struktur yang digunakan secara umum di kampung fashion etnik fashion etnik ini adalah struktur rangka sistem grid. Struktur rangka adalah sistem yang akan menumpu kolom dan balok serta 
sebagai penyusun fungsi-fungsi ruang di dalamnya.

Adapun bagian-bagian struktur yang digunakan: struktur bagian bawah pondasi umpak dan batu kali pada bangunan 1 lantai serta footplat pada bangunan lebih dari 1 lantai. Struktur tengah diisi oleh dinding bata dengan struktur tiang (non bearing wall). Terakhir, struktur atas adalah atap dengan sistem kuda-kuda dan gunungan.

Untuk menghasilkan struktur dan bentuk tersebut maka diperlukan bahan bangunan dengan pertimbangan: karakter kampung fashion etnik dan fashion etnik, kualitas terhadap iklim dan cuaca, kenyamanan untuk bersentuhan dengan pengguna saat berkegiatan, dan kesesuaian dengan lingkungan. Salah satu aspek arsitektural yang dapat menghasilkan keaslian pada bangunan Kampung fashion etnik Fashion Etnik ini adalah penggunaan bahan material bangunan yang digunakan oleh masyarakat Sukoharjo dan dihasilkan di Sukoharjo, terutama lingkungan pengrajin fashion etniknya. Bahan material khas yang digunakan oleh masyarakat Sukoharjo dalam konstruksi antara lain: tegel kunci, rooster, bata, batu alam, semen, beton, kayu, genteng tanah liat, dan bambu baik itu bersifat permanen maupun semi permanen. Bahan material yang khas buatan Sukoharjo adalah bata yang dapat diekspose, batu alam, ubin, serta genteng tanah liat yang masih diproduksi di daerah Mojolaban, Polokarto, dan Sukoharjo.

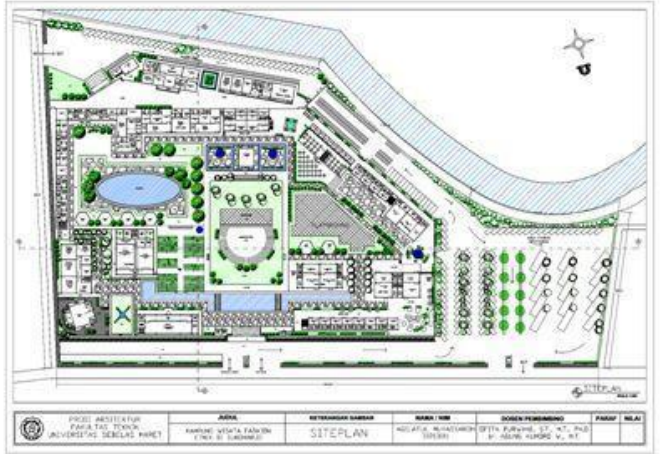

Gambar 2. Siteplan Hasil

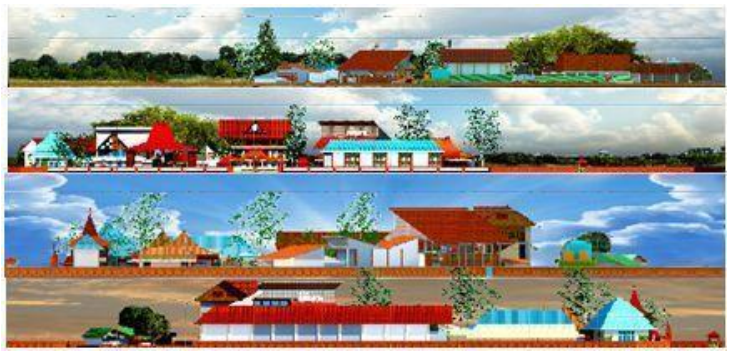

Gambar 3. Tampak Hasil

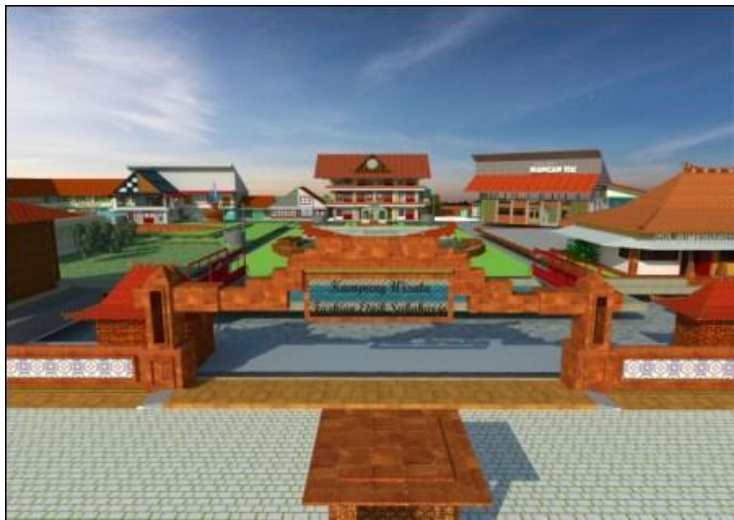

Gambar 4. Perspektif Eksterior Hasil

\section{KESIMPULAN}

Sebuah pengembangan wisata dapat diselesaikan dengan arsitektur, tak terkecuali potensi industri fashion etnik. Hal utama yang perlu diperhatikan adalah bagaimana cara memenuhi komponen wisata dengan cara arsitektur agar terbentuk destinasi wisata yang baik.

Aspek arsitektur yang tidak kalah penting lainnya setelah bentuk fisik adalah sistem utilitas bangunan. Pengadaan air bersih yang merupakan unsur vital dalam berkegiatan manusia bersumber dari sumur deep well dengan 
sistem downfeed serta sumur tradisional. Permasalahan yang ditimbulkan dari proses pengerjaan fashion etnik adalah penanganan air kotor bekas pewarnaan kimia, diselesaikan dengan sistem IPAL (Instalasi Pengolahan Air Limbah) sehingga baru dibuang ke riool kota setelah mengalami filterisasi akhir. Penanganan air hujan memanfaatkan sistem talang dan pembuangan melalui riool kota (selokan). Sampah-sampah yang dihasilkan dikumpulkan secara terpisah menurut jenisnya, yakni: sampah kain sisa pemotongan: dikelola secara kreatif dan mandiri, sampah organik: dijadikan pupuk, serta sampah anorganik: didaur ulang untuk sampah seperti plastik dan dikubur agar cepat hancur untuk sampah kertas. Untuk jaringan telekomunikasi menggunakan PABX sehingga memperlancar akses internet bagi pedagang di online-shop. Untuk pembahasan terakhir, yakni pengamanan produk fashion etnik dan penggunanya terhadap bahaya kebakaran lebih spesifik yakni menggunakan peralatan sistem sprinkler, hydrant, serta APAR.

\section{REFERENSI}

AlSayyad, Nezar. 2001. "Consuming Tradition, Manufacturing Heritage: Global Norms and Urban Forms in the Age of Tourism". Psychology Press.

Media, Joglosemar Prima, and Joglosemar Prima Media $2016 \quad$ Kunjungan Wisatawan Ke

Solo Terus Meningkat. JOGLOSEMAR.CO. https://joglosemar.co/2016/03/kunju ngan-wisatawan-solo-terusmeningkat.html, accessed March 31, 2017.

Neufert, Ernst. 1996. "Data Arsitek Jilid 1 Edisi 33". Jakarta: Erlangga.

Pendit, Nyoman S. 1986. "Ilmu pariwisata: sebuah pengantar perdana". Pradnya Paramita.

Soetiadji S., Ir. Setyo. 1997. "Anatomi Denah, Tampak, Potongan, Struktur, Estetika,Utilitas". Jakarta: Djambatan.
Urry, John. 2002. "The Tourist Gaze". SAGE.

Wahab, Salah. 1975. "Wahab on Tourism Management: An Introduction to the Scientific Study of Tourism Management, Aimed at Those Who Recognise the Rewards of a Well Managed Tourism Industry, and Who Perceive the Penalties of Mismanagement". Tourism International Press.

Yoeti, Oka A. 1983. "Pengantar Ilmu Pariwisata / Oka A. Yoeti, Pengantar Ilmu Pariwisata / Oka A. Yoeti. 1. PARIWISATA,Pengantar Ilmu Pariwisata "/ Oka A. Yoeti, Pengantar Ilmu Pariwisata / Oka A. Yoeti 1983(1983): 1-99.

www.solopos.net

mediaindonesia.com 